\title{
EFEITOS DE IMIDAZOLINONAS E SULFONILURÉIAS SOBRE A PRODUÇÃO DE SEMENTES E EMERGÊNCIA DE PLANTULAS DE QUINQUILHO ${ }^{1}$
}

\author{
ANDRÉ ANDRES ${ }^{2}$ e NILSON G. FLECKS ${ }^{3}$
}

\begin{abstract}
Em 1990, 91 e 92 foi conduzido ensaio na Faculdade de Agronomia da UFRS, em Porto Alegre, RS, cujo objetivo foi investigar os efeitos de herbicidas aplicados durante a fase reprodutiva de quinquilho (Datura stramonium). Foram testados dois compostos imidazolinonas (imazaquin e imazethapyr) e duas sulfoniluréias (chlorimuron e metsulfuron) sobre a produção de sementes e viabilidade e germinação das sementes formadas. Todas as aplicações herbicidas realizadas no florescimento, exceto metsulfuron na meia-dose, reduziram em mais de $75 \%$ a produção de sementes. As aplicações herbicidas efetuadas no florescimento de quin
\end{abstract}

RESUMO quilho reduziram em $76 \%$ o número de sementes por planta em comparação aos tratamentos aplicados no enchimento de grãos. Na avaliação da viabilidade das sementes não se constatou efeitos dos herbicidas testados. Herbicidas aplicados na fase reprodutiva de quinquilho permitiram reduzir a perpetuação da mesma por diminuir a produção de suas sementes.

Palavras-chave: Características reprodutivas, viabilidade das sementes, aplicações tardias, germinação, Datura stramonium.

\section{ABSTRACT \\ Effects of imidazolinones and sulfonylureas on jimsonweed seed production and seedling emergence}

A trial was conducted in 1990, 91 and 92 at Federal University of Rio Grande do Sul, in Porto Alegre, RS, Brazil, to investigate the effects of herbicides applied at the reproductive period of jimsonweed (Datura stramonium). Two imidazolinones (imazaquin and imazethapyr) and two sulfonylureas (chlorimuron and metsulfuron), which were tested for their effect on the number of seeds produced, seed viability and seed germination. All compounds applied at flowering stage, except half rate of metsulfuron, reduced by

\section{INTRODUÇÃO}

Normalmente, as plantas daninhas que escapam aos métodos iniciais de controle ou que emergem tardiamente more than $75 \%$ the number of seeds produced. Herbicide applications at flowering stage reduced seed production by $76 \%$ in comparison with plants sprayed at grain filling stage. Jimsonweed seed viability was not affected by the treatments. Herbicides applied during jimsonweed reproductive stage reduce its survival by decreasing seed production.

Additional index words: Reproductive characteristics, seed viability, late applications, Datura stramonium, seed germination.

podem produzir quantidades de sementes que assegurem infestações nos anos subseqüentes, em áreas já infestadas ou em outras áreas isentas delas.

Esforços para evitar a produção de sementes e/ou inviabilizar sua germinação posterior são raros, pois as

\footnotetext{
${ }^{1}$ Recebido para publicação em 04/01/94 e na forma revisado em 12/08/'94. Extraído da dissertação do primeiro autor para obtenção do grau de Mestre em Fitotecnia pela Faculdade de Agronomia da UFRS. Parcialmente financiado pelo CNPq.

${ }^{2}$ Eng $^{\circ}$ Agr $^{\circ}$, Pós-Graduação em Agronomia, Faculdade de Agronomia, UFRS, Caixa Posta1 776, Porto Alegre, RS $90001-970$

${ }^{3}$ Eng $^{\circ}$ Agr $^{\mathrm{a}}$, PhD, Prof. Adjunto, Bolsista do CNPq, Dep. de Plantas de Lavoura, Faculdade de Agronomia, UFRS, Caixa Postal 776, Porto Alegre, RS 90001-970
} 
infestações que restam após o término do controle das plantas daninhas, empregado no início da estação de crescimento da cultura, normalmente não afetam seu rendimento e, portanto, geralmente nenhum método é utilizado com esta finalidade.

Quinquilho é uma espécie pertencente à família das Solanáceas que apresenta ciclo anual e que se reproduz exclusivamente por sementes, sendo considerada problema principalmente para lavouras de soja no Estado do Rio Grande do Sul (Lorenzi, 1991). Infestações de quinquilho podem reduzir em mais de $50 \%$ o rendimento da soja por efeito de interferência (Henry \& Baumam, 1991). A espécie apresenta prolífica produção de sementes, mais de 20.000 por planta, as quais apresentam dormência (Henry \& Baumam, 1991; Levitt \& Lovett, 1984; Weaver \& Warwich, 1984), tendo sido constatada grande longevidade das mesmas (Ross \& Lembi, citado por Garcia-Torres \& FernandezQuintanilla, 1991) e também heterogeneidade de emergência (Pawlak et al., 1990). Estas características contribuem para as vantagens competitivas de quinquilho, bem como para a importância desta espécie no contexto agronômico.

A aplicação de herbicidas durante a fase reprodutiva de plantas daninhas tem reduzido a produção e/ou a germinação em algumas espécies (Biniak \& Aldrich, 1986; Isaacs et al., 1989; Maun \& Cavem, 1969; Tayloison, 1966). Aplicações de dalapon em diferentes doses no início do período reprodutivo de quinquilho reduziu em $100 \%$ a produção de sementes (Fawcet \& Slife, 1978). A produção de sementes de Rumex crispus (língua-de-vaca) foi reduzida em quase $100 \%$ com aplicações de 2,4-D antes ou após o florescimento, e sua germinação também foi reduzida (Maun \& Cavem, 1969). A emergência de plântulas de Cassia obtusifolia (fedegoso) foi reduzida em $90 \%$ por aplicações de glifosate no início da frutificação, enquanto a produção de sementes sofreu decréscimo de $84 \%$ com aplicações no início do florescimento (Isaacs et al., 1989).

Analisando os trabalhos citados, notou-se que é possível não só reduzir a produção de sementes de plantas daninhas ainda na planta-mãe, como também atingir sua viabilidade. Os métodos direcionados em atingir a viabilidade das sementes representam potencial ideal para reduzir o reabastecimento da população de sementes no solo.

Herbicidas pertencentes aos grupos químicos das imidazolinonas e sulfoniluréias, tem sido investigados principalmente para o controle de plantas daninhas dicotiledôneas na cultura da soja (Claus, 1987; Congleton et al., 1987). Como são grupos químicos de recente desenvolvi mento, seus efeitos na produção e viabilidade de sementes de plantas tratadas tardiamente tem sido pouco estudados. Entretanto, por sua pronta translocação e por se acumularem em tecidos meristemáticos, exercendo ação sobre a divisão celular em plantas suscetíveis (Claus, 1987; Congleton et al., 1987; Ray, 1984; Shaner et al., 1984), apresentam potencial para aplicações na fase inicial do período reprodutivo das plantas daninhas, com a finalidade de impedir o pleno desenvolvimento das sementes e/ou resultar em produção de sementes inviáveis, reduzindo o potencial de reinfestação destas plantas (Isaacs et al., 1989).

Caso estes herbicidas possam ser aplicados em estádios específicos do desenvolvimento reprodutivo de quin quilho, de forma que reduzam o retorno de sementes viáveis ao solo, sem apresentar efeito adverso na cultura, pode-se definir este uso como um programa de médio a longo prazo de manejo das infestações de quinquilho. Desta forma, este trabalho teve como objetivo avaliar os efeitos de quatro herbicidas aplicados na fase reprodutiva de quinquilho sobre a produção e a viabilidade de suas sementes.

\section{MATERIAL E MÉTODOS}

O experimento foi conduzido em campo, em 1990, e complementado em casa-de-vegetação e em laboratório em 1991 e 1992, tendo sido executado no Departamento de Plantas de Lavoura da Universidade Federal do Rio Grande do Sul, em Porto Alegre, RS, e também no Laboratório de Análise e Tecnologia de Sementes do Instituto de Pesquisas Agronômicas (IPAGRO), da Secretaria da Agricultura e Abastecimento do Rio Grande do Sul.

Sementes de quinquilho foram postas a germinar em vasos confeccionados com material orgânico mantidos sob ambiente natural, em viveiro, onde as plântulas permaneceram até a data de transplante ao local definitivo. A densidade média de quinquilho transferido ao campo foi de quatro plantas $/ \mathrm{m}^{2}$, utilizando-se espaçamento de $0,5 \mathrm{~m}$ entre plantas e entre linha.

Utilizou-se o delineamento experimental inteiramente casualizado, em esquema fatorial $(4 \times 2 \times 2)$, com herbicidas, doses (recomendada e meia-dose) e épocas de aplicação (florescimento e enchimento de grãos) como fatores. Os herbicidas metsulfuron, chlorimuron, imazaquin e imazethapyr, seus respectivos grupos químicos e doses utilizadas constam da Tabela 1.

A aplicação dos herbicidas foi realizada com auxílio de aparelho pulverizador costal de precisão, mantendo-se a pressão constante. $\mathrm{O}$ aparelho esteve munido de um bico leque, especificação 8002 , operado à pressão de $150 \mathrm{kPa}$ e utilizando volume de calda correspondente a $500 \mathrm{I} / \mathrm{ha}$.

A pulverização foi realizada individualmente sobre cada planta (uma por tratamento), sendo os estádios estabelecidos quando, no caso do florescimento, havia aproximadamente $60 \%$ de flores abertas em relação ao número de botões florais e, para enchimento de grãos o foi quando cerca de $70 \%$ dos frutos das plantas apresentavam da base ao ápice tamanho superior a $1 \mathrm{~cm}$. As plantas pulverizadas no primeiro estádio não foram tratadas no segundo e viceversa. As plantas testemunhas não foram pulverizadas.

A coleta dos frutos foi realizada quando estes apresentavam coloração marrom-clara e, ao se abrirem, possibilitavam a visualização das sementes completamente maduras, sem ter ainda havido deiscência destas. Foram realizadas quatro coletas de frutos $(105,120,140$ e 150 dias após a emergência), em função da heterogeneidade de maturação apresentada pela espécie daninha. Os frutos e sementes colhidos foram acondicionados em sacos de papel e conservados no refrigerador à temperatura próxima de $0^{\circ} \mathrm{C}$ durante 45 dias. Após a separação das sementes dos frutos, foi efetuada a contagem dos frutos e pesagem do total de sementes por planta. Foi retirada uma amostra de 400 sementes de 
TABELA 1 - Herbicidas, doses e grupos químicos utilizados no experimento a campo. Porto Alegre, RS, 1990/91.

\begin{tabular}{|c|c|c|c|c|c|c|}
\hline \multirow{2}{*}{$\begin{array}{c}\begin{array}{c}\text { Nome } \\
\text { comum }^{\mathrm{a}}\end{array} \\
\text { Metsulfuron }\end{array}$} & \multirow{2}{*}{$\begin{array}{l}\text { Grupo químico } \\
\text { Sulfoniluréia }\end{array}$} & \multirow{2}{*}{$\begin{array}{c}\begin{array}{c}\text { Formulação e } \\
\text { concentração }\end{array} \\
\mathrm{GD}^{\mathrm{c}}, 600 \mathrm{~g} / \mathrm{kg}\end{array}$} & \multicolumn{2}{|c|}{ Doses $^{\text {b }}$ (g i.a./ha) } & \multicolumn{2}{|c|}{ Adjuvante e concentraçäo } \\
\hline & & & 2,4 & 1,2 & - & - \\
\hline Chlorimuron & Sulfoniluréia & $\mathrm{GD}, 250 \mathrm{~g} / \mathrm{kg}$ & 60 & 30 & - & - \\
\hline Imazaquin & Imidazolinona & $\mathrm{SA}^{\mathrm{d}}, 100 \mathrm{~g} / \mathrm{l}$ & 100 & 50 & Renex & $0,5 \% \mathrm{v} / \mathrm{v}$ \\
\hline Imazethapyr & Imidazolinona & $\mathrm{SA}, 150 \mathrm{~g} / \mathrm{l}$ & 150 & 75 & Renex & $0,5 \% \mathrm{v} / \mathrm{v}$ \\
\hline
\end{tabular}

- Nomes comerciais: Ally, Classic, Scepter e Pivot, respectivamente,

b Equivalentes à usual e à metade desta.

- $\mathrm{GD}=\mathrm{Grânulos}$ dispersiveis em água.

¿ $\mathrm{SA}=$ Soluçāo aquosa.

cada unidade experimental para determinação do peso de 1000 sementes.

Em casa-de-vegetação, foram postas a germinar 50 sementes de quinquilho em solo acondicionado em vasos plásticos com capacidade para $500 \mathrm{~g}$ de solo peneirado, utilizando-se quatro repetições por tratamento. Transcorridos 65 dias após a semeadura, foi considerada finalizada a emergência das plântulas e os dados foram convertidos em valores percentuais que corresponderam à emergência da espécie.

Em laboratório, foi realizado teste de tetrazólio (Grabe, 1976), com a finalidade de verificar o percentual de sementes vivas após transcorridos aproximadamente 13 meses da aplicação dos tratamentos a campo. Este teste permitiu quantificar o número de sementes viáveis ou mortas, em resposta aos tratamentos. Para realização deste teste foram separadas 50 sementes de cada unidade experimental. Os dados obtidos pela contagem de embriões vivos foram transformados em valores percentuais que corresponderam à viabilidade das sementes do respectivo lote.

As variáveis estudadas no experimento foram submetidas a duas análises de variância. A primeira envolveu delineamento constituído pelos quatro herbicidas, duas doses e duas épocas de aplicação, sem a inclusão da testemunha. Com a verificação da significância estatística efetuou-se a comparação das médias através do teste de Duncan, ao nível de $1 \%$ de probabilidade. Através desta análise foi possível comparar herbicidas, épocas de aplicação e doses herbicidas e também as respectivas interações. Considerando o nível de significância empregado (1\%), as interações pouco contribuíram para esclarecer os resultados sob ponto de vista biológico, sendo assim as mesmas foram desconsideradas. Em outra análise de variância foi incluída a testemunha, realizando-se o teste ' $t$ ' de contrastes para verificar a significância entre os tratamentos e a testemunha. Posteriormente, fez-se necessário aplicar o teste bilateral de Dunnett ao nível de $1 \%$ de probabilidade para diferenciar os tratamentos herbicidas da testemunha.

\section{RESULTADOS E DISCUSSÃO}

As plantas testemunhas de quinquilho produziram, durante o ciclo, médias de 41 frutos e de 10336 sementes por indivíduo (Tabela 2). Estes resultados não alcançaram os valores encontrados em outros trabalhos (Henry \& Baumam, 1991; Levitt \& Lovett, 1984; Weaver \& Warwich, 1984) que referiram a produção de mais de 20.000 sementes por planta. Saliente-se que a ocorrência de reduzidas precipitações e a incidência de altas temperaturas durante o período do ensaio, especialmente durante a fase reprodutiva, possam ter levado a planta ao estresse hídrico por deficiência, o que pode ter prejudicado a expressão de seu potencial reprodutivo (Sanchez et al., 1981). Como a diferenciação floral é responsável pela determinação do número de frutos e sementes das plantas, provavelmente esta fase coincidiu com período de deficiência hídrica, reduzind o a produtividade do quinquilho.

Modificações no número, peso, emergência e viabilidade das sementes produzidas são alguns dos resultados encontrados. Porém, outros autores referem a possibilidade dos efeitos atingirem apenas o desenvolvimento da plântula ori ginada desta semente (Biniak \& Aldrich, 1984; Fawcet \& Slife, 1978; Isaacs et al., 1989; Ratnayake \& Shaw, 1992).

Como a pulverização dos herbicidas ocorreu na fase reprodutiva, esperava-se também que seu efeito na formação das sementes dar-se-ia através da inibição da viabilidade ou germinação destas. Tais efeitos poderiam ocorrer de dois modos. A tran slocação de moléculas herbicidas até o embrião em desenvolvimento poderia torná-lo inviável através de sua ação em alguma via metabólica ou atuando sobre a síntese de aminoácidos, interferir na divisão celular, impedindo uma formação íntegra da semente. A outra possibilidade seria através de seu acúmulo em tecidos de reserva para posterior liberação e atuação sobre a semente em germinação (Biniak \& Aldrich, 1986; Fawcet \& Slife, 1978; Isaacs et al., 1989; Ratnayake \& Shaw, 1992).

A redução na produção de frutos e sementes foi elevada quando os herbicidas foram aplicados no florescimento, em comparação a sua aplicação no enchimento de grãos (Tabela 3). No florescimento as plantas tratadas sofreram reduções nas suas produções de frutos acima de 78\%: metsulfuron a 2,4 g/ha (redução de $83 \%$ ); chlorimuron a 30 e 60 $\mathrm{g} / \mathrm{ha}$ (reduções de $78 \%$ e $80 \%$, respectivamente); imazaquin a 75 e $150 \mathrm{~g} / \mathrm{ha}$ (reduções de $88 \%$ e $95 \%$, respectivamente); e imazethapyr a 50 e $100 \mathrm{~g} / \mathrm{ha}$ (reduções de $95 \%$ e $90 \%$, respectivamente) (Tabela 2 ). A baixa produção de sementes nas plantas tratadas no florescimento pode estar associada ao modo de ação destes herbicidas, pois ao serem absorvidos e translocados às regiões meristemáticas, impedem a divisão 
TABELA 2 - Características de reproduçẩo das plantas de quinquilho em função da aplicaçảo de herbicidas na fase reprodutiva. Porto Alegre, RS, 1990/91.

\begin{tabular}{|c|c|c|c|c|c|}
\hline \multirow{2}{*}{$\begin{array}{c}\text { Tratamentos } \\
\text { Herbicida/ } \\
\text { dose }(\mathrm{g} / \mathrm{ha}) / \\
\text { época }\end{array}$} & \multicolumn{5}{|c|}{ Características } \\
\hline & $\begin{array}{c}\text { Frutos } \\
\text { por planta }\end{array}$ & $\begin{array}{l}\text { Sementes } \\
\text { por fruto }\end{array}$ & $\begin{array}{l}\text { Sementes } \\
\text { por planta }\end{array}$ & $\begin{array}{c}\text { Peso de } \\
\text { mil sementes } \\
\text { (g) }\end{array}$ & $\begin{array}{c}\text { Peso total de } \\
\text { sementes por planta } \\
\text { (g) }\end{array}$ \\
\hline Metsulfuron/1,2/flor. ${ }^{1}$ & $22 \mathrm{NS}$ & $182 \mathrm{NS}$ & $4.027 \mathrm{NS}$ & $5,66 \mathrm{NS}$ & $22,79 \mathrm{NS}$ \\
\hline Metsulfuron/2,4/flor. & $7^{* *}$ & $205 \mathrm{NS}$ & $1.444^{* *}$ & $4,62 \mathrm{NS}$ & $6,67^{* *}$ \\
\hline Metsulfuron/1,2/ench. ${ }^{2}$ & $17 \mathrm{NS}$ & $231 \mathrm{NS}$ & 3.974 NS & $4,90 \mathrm{NS}$ & $19,45^{* *}$ \\
\hline Metsulfuron/2,4/ench. & $20 \mathrm{NS}$ & $191 \mathrm{NS}$ & $3.734 \mathrm{NS}$ & $5,54 \mathrm{NS}$ & $20,70^{* *}$ \\
\hline Chlorimuron/30/flor. & $9 * *$ & $210 \mathrm{NS}$ & $1.841^{* *}$ & $4,21 \mathrm{NS}$ & $7,75^{* *}$ \\
\hline Chlorimuron/60/flor. & $8^{* *}$ & $124 \mathrm{NS}$ & $1.002 * *$ & $3,69 * *$ & $3,70^{* *}$ \\
\hline Chlorimuron/30/ench. & $15 \mathrm{NS}$ & $282 \mathrm{NS}$ & $4.304 \mathrm{NS}$ & $5,22 \mathrm{NS}$ & $22,48 \mathrm{NS}$ \\
\hline Chlorimuron/60/ench. & $18 \mathrm{NS}$ & $238 \mathrm{NS}$ & $4.378 \mathrm{NS}$ & $5,49 \mathrm{NS}$ & $24,04 \mathrm{NS}$ \\
\hline Imazaquin/ 75/flor. & $5 * *$ & 134 NS & $640 * *$ & $4,05 * *$ & $2,59 * *$ \\
\hline Imazaquin/150/flor. & $2 * *$ & $93 \mathrm{NS}$ & $192 * *$ & $3,43^{* *}$ & $0,66^{* *}$ \\
\hline Imazaquin/ 75/ench. & $18 \mathrm{NS}$ & $238 \mathrm{NS}$ & $4.390 \mathrm{NS}$ & $5,49 \mathrm{NS}$ & $24,11 \mathrm{NS}$ \\
\hline Imazaquin/150/ench. & $12 \mathrm{NS}$ & $247 \mathrm{NS}$ & $2.936 \mathrm{NS}$ & $5,46 \mathrm{NS}$ & $16,03^{* *}$ \\
\hline Imazethapyr/ 50/flor. & $2^{* *}$ & $143 \mathrm{NS}$ & $291^{* *}$ & $5,67 \mathrm{NS}$ & $1,65^{* *}$ \\
\hline Imazethapyr/100/flor. & $4^{* *}$ & $93 \mathrm{NS}$ & $418^{* *}$ & 3,13 ** & $1,31^{* *}$ \\
\hline Imazethapyr/ 50/ench. & $17 \mathrm{NS}$ & $249 \mathrm{NS}$ & $4.304 \mathrm{NS}$ & $5,10 \mathrm{NS}$ & $21,97 \mathrm{NS}$ \\
\hline Imazethapyr/100/ench. & $15 \mathrm{NS}$ & $161 \mathrm{NS}$ & $2.424 * *$ & 4,99 NS & $12,09 * *$ \\
\hline Testemunha & 41 & 251 & 10.336 & 6,23 & 64,37 \\
\hline CV (\%) & 30,2 & 31,9 & 39,1 & 16,6 & 33,7 \\
\hline
\end{tabular}

1 Florescimento.

2 Enchimento de grăos.

NS Médias comparadas com a testemunha nas colunas, nāo diferem significativamente pelo teste bilateral de Dunnett, ao nível de $1 \%$ de probabilidade.

** Médias comparadas com a testemunha nas colunas, diferem significativamente pelo teste bilateral de Dunnett ao nível de $1 \%$ de probabilidade.

celular e causam a morte dos tecidos, além de outros sintomas, como encarquilhamento e clorose foliar (Claus, 1987; Ray, 1988). 0 decréscimo na produção de sementes também pode ser devido à rápida morte da planta causada pelos herbicidas (menor ciclo de vida em relação à testemunha), e pela rápida abscissão das estruturas reprodutivas quando das aplicações precoces (Fawcet \& Slife, 1978; Isaacs et al., 1989; Ratnayake \& Shaw, 1992).

Investigando o desenvolvimento de sementes de leguminosas, Isaacs et al. (1989) encontraram que a divisão celular do embrião é rápida no período seguinte à fecundação, mas diminui e cessa antes do embrião atingir metade do máximo de seu peso seco. Isto explica, em parte, o aumento da eficiência das aplicações herbicidas nos estádios iniciais do desenvolvimento reprodutivo, especialmente para os compostos testados, cujas moléculas são de pronta translocação para tecidos meristemáticos e são potentes inibidores da divisão celular (Beyer et al., 1988; Claus, 1987; Congleton et al., 1987; Shaner et al., 1984). A presença de maiores quantidades de reservas proteicas disponíveis para remobilização a aminoácidos, pode tornar mais lento o efeito dos herbicidas (Shaner et al., 1984). Talvez este fato também possa estar associado com a capacidade da própria planta em degradar ou desativar tais compostos em maior velocidade, de modo que tenha contribuído para elevar sua tolerância aos herbicidas (Gressel, 1985). Pode-se salientar ainda, que as plantas sofreram estresse hídrico por deficiência durante o período do ensaio e, como no enchimento de grãos a espécie ainda se encontrava exercendo forte competição por luz e água, pode ter havido redução da produtividade em função destes fatores.

Na comparação da produção de frutos por planta, quanto aos herbicidas usados, houve redução no número de frutos produzidos com o uso de imazaquin em relação ao metsulfuron, enquanto que imazethapyr e chlorimuron produziram número intermediário de frutos (Tabela 3). Não foram constatadas diferenças entre doses herbicidas testadas. Já a aplicação dos herbicidas no florescimento promoveu redução de $59 \%$ neste parâmetro quando comparada à aplicação no enchimento de grãos (Tabela 3).

Os frutos das plantas testemunhas produziram, em média, 251 sementes (Tabela 2). Embora algumas aplicações herbicidas reduzissem, em valores absolutos, em até $63 \%$ o número de sementes por fruto, não se constataram diferenças 
TABELA 3 - Características de reprodução das plantas de quinquilho em funçáo da aplicaçảo de herbicidas na fase reprodutiva. Porto Alegre, RS, 1990/91.

\begin{tabular}{|c|c|c|c|c|c|}
\hline \multirow{2}{*}{$\begin{array}{c}\text { Tratamentos } \\
\text { Fatores e níveis }\end{array}$} & \multicolumn{5}{|c|}{ Características } \\
\hline & $\begin{array}{c}\text { Frutos } \\
\text { por planta }\end{array}$ & $\begin{array}{l}\text { Sementes } \\
\text { por fruto }\end{array}$ & $\begin{array}{l}\text { Sementes } \\
\text { por planta }\end{array}$ & $\begin{array}{c}\text { Peso de } \\
\text { mil sementes } \\
\text { (g) }\end{array}$ & $\begin{array}{c}\text { Peso total de } \\
\text { sementes por planta } \\
\text { (g) }\end{array}$ \\
\hline \multicolumn{6}{|l|}{ Herbicidas } \\
\hline Imazaquin & $8 \mathrm{~b}^{\circ}$ & $129 \mathrm{a}$ & $1.465 \mathrm{a}$ & 4,61 a & 8,49 a \\
\hline Imazethapyr & $9 \mathrm{ab}$ & $138 \mathrm{a}$ & $1.401 \mathrm{a}$ & $4,72 \mathrm{a}$ & 7,35 a \\
\hline Chlorimuron & $12 \mathrm{ab}$ & 167 a & 2.543 a & 4,65 a & 13,02 a \\
\hline Metsulfuron & 16 a & $181 \mathrm{a}$ & $3.078 \mathrm{a}$ & 5,18 a & 16,70 a \\
\hline \multicolumn{6}{|l|}{ Doses"* } \\
\hline Meia-dose & 12 a & 179 a & $2.553 \mathrm{a}$ & 5,04 a & 13,57 a \\
\hline Dose-plena & $10 \mathrm{a}$ & 129 a & $1.622 \mathrm{a}$ & 4,54 a & 8,89 a \\
\hline \multicolumn{6}{|l|}{ Épocas de aplicaçã̃o } \\
\hline Florescimento & $7 \mathrm{~b}$ & $94 \mathrm{~b}$ & $888 \mathrm{~b}$ & $4,31 \mathrm{~b}$ & $4,71 \mathrm{~b}$ \\
\hline Enchimento de grãos & $17 \mathrm{a}$ & 226 a & $3.722 \mathrm{a}$ & 5,27 a & 19,91 a \\
\hline CV (\%) & 32,38 & 33,41 & 42,73 & 17,4 & 36,66 \\
\hline
\end{tabular}

- Médias comparadas dentro de cada fator, nas colunas, seguidas de mesma letra, nāo diferem significativamente entre si pelo teste de Duncan, ao nível de $1 \%$ de probabilidade.

** Correspondentes à metade da dose usual $\mathrm{e}$ à dose recomendada, respectivamente.

significativas entre os tratamentos testados, provavelmente devido ao elevado coeficiente de variação desta característica (Tabela 2). Encontrou-se 58\% de redução no número de sementes produzidas por fruto com aplicação dos herbicidas no estádio de florescimento em relação às aplicações no enchimento de grãos (Tabela 3). Já para os demais fatores investigados não se constataram diferenças.

Uma vez formada a cápsula, esta provavelmente já tenha manifestado sua plena capacidade reprodutiva. Portanto, resta para a planta balancear o peso das sementes fixadas através da redução do suprimento de assimilados, devido à redução de folhas, ramos e caule (Biniak \& Aldrich, 1986). Como os herbicidas atuam em inibir a divisão celular (Beyer et al., 1988), a fonte para estes assimilados fica prejudicada e, este fato torna claro a obtenção de muitas cápsulas de quinquilho contendo sementes não desenvolvidas.

A aplicação dos herbicidas, principalmente no período de florescimento da espécie daninha, foi bastante eficiente em reduzir a formação das sementes, sendo que apenas metsulfuron na meia-dose não proporcionou decréscimo significativo. (Tabela 2). Já no enchimento de grãos, a pulverização herbicida pouco afetou a formação e produção de sementes por planta, destacando-se somente aplicação de imazethapyr a $100 \mathrm{~g} / \mathrm{ha}$ que causou redução de $76 \%$ nesta variável em relação à testemunha.

Quanto à época de aplicação dos herbicidas, quando esta foi efetuada no florescimento da espécie, ocorreu redução de $76 \%$ no número de sementes produzidas em relação aos tratamentos utilizados no enchimento de grãos (Tabela 3). Não houve diferenças entre os herbicidas testados e tampouco entre as doses de aplicação (Tabela 3 ).
O peso de 1000 sementes foi reduzido em $41 \%$ em relação à testemunha com aplicação da dose-plena de chlorimuron no florescimento, enquanto que imazaquin aplicado nas duas doses e imazethapyr na dose-plena, neste mesmo estádio, proporcionaram decréscimos de 35,45 e $48 \%$, respectivamente, no peso desta variável (Tabela 2 ).

A análise estatística dos dados de emergência evidenciou diferença entre testemunha e o tratamento com imazethapyr aplicado na dose-plena no enchimento de grãos, tendo ocorrido redução de $77 \%$ na emergência de quinquilho. Para os demais tratamentos não foram constatadas diferenças. Porém, para comprovar esta redução, foi realizado teste de tetrazólio, quando se avaliou a viabilidade das sementes, não ocorrendo diferenças entre testemunha e tratamentos herbicidas (Tabela 4). A análise estatística também mostrou que não houve comportamento diferenciado entre compostos herbici das, doses e épocas de aplicação na emergência e na viabilidade das sementes (Tabela 5).

Apesar de que a viabilidade das sementes, obtida através do teste de tetrazólio, não comprovasse nenhuma redução desta variável, ficou demonstrado que a espécie ainda mostrava sinais de dormência no período do teste, pois enquanto a testemunha mostrou emergência de $32 \%$ a mesma obteve no teste de tetrazólio, $58 \%$ de viabilidade. Este fato vem comprovar afirmação de Gutterman (1985), de que as espécies daninhas, em condições favoráveis ou não, possuem um mecanismo de sobrevivência que as possibilitam produzir lotes de sementes com variação na germinação, o que permite a perpetuação da espécie em qualquer ambiente (heteroblastia). Cita o autor, que dentro de uma mesma planta, é 
TABELA 4 - Emergência das plântulas e viabilidade das sementes de quinquilho oriundas de plantas-máe pulverizadas por herbicidas na fase reprodutiva. Porto Alegre, RS, 1991/92.

\begin{tabular}{l|c|c}
\hline \multicolumn{1}{c|}{ Tratamentos } & \multicolumn{2}{|c}{ Características } \\
\hline $\begin{array}{c}\text { Herbicida/dose/época } \\
(\mathrm{g} / \mathrm{ha})\end{array}$ & $\begin{array}{c}\text { Emergência } \\
\text { das plântulas } \\
(\%)\end{array}$ & $\begin{array}{c}\text { Viabilidade } \\
\text { das sementes } \\
(\%)\end{array}$ \\
\hline $\begin{array}{l}\text { Metsulfuron/1,2/flor. } \\
{ }^{1}\end{array}$ & $23,9 \mathrm{NS}$ & $51,1 \mathrm{NS}$ \\
Metsulfuron/2,4/flor. & $22,5 \mathrm{NS}$ & $50,1 \mathrm{NS}$ \\
Metsulfuron/1,2/ench. & $20,3 \mathrm{NS}$ & $62,8 \mathrm{NS}$ \\
Metsulfuron/2,4/ench. & $29,2 \mathrm{NS}$ & $62,5 \mathrm{NS}$ \\
Chlorimuron/30/flor. & $17,7 \mathrm{NS}$ & $50,5 \mathrm{NS}$ \\
Chlorimuron/60/flor. & $19,9 \mathrm{NS}$ & $36,3 \mathrm{NS}$ \\
Chlorimuron/30/ench. & $19,9 \mathrm{NS}$ & $51,0 \mathrm{NS}$ \\
Chlorimuron/60/ench. & $18,3 \mathrm{NS}$ & $64,0 \mathrm{NS}$ \\
Imazaquin/ 75/flor. & $13,5 \mathrm{NS}$ & $49,7 \mathrm{NS}$ \\
Imazaquin/150/flor. & $23,9 \mathrm{NS}$ & $38,0 \mathrm{NS}$ \\
Imazaquin/ 75/ench. & $22,4 \mathrm{NS}$ & $65,2 \mathrm{NS}$ \\
Imazaquin/150/ench. & $12,6 \mathrm{NS}$ & $59,9 \mathrm{NS}$ \\
Imazethapyr/ 50/flor. & $22,0 \mathrm{NS}$ & $44,4 \mathrm{NS}$ \\
Imazethapyr/100/flor. & $9,9 \mathrm{NS}$ & $37,9 \mathrm{NS}$ \\
Imazethapyr/ 50/ench. & $10,4 \mathrm{NS}$ & $42,4 \mathrm{NS}$ \\
Imazethapyr/100/ench. & $7,3 * *$ & $42,5 \mathrm{NS}$ \\
Testemunha & 32,0 & 58,4 \\
\hline CV (\%) & 26,3 & 22,2 \\
\hline
\end{tabular}

I Florescimento.

'Enchimento de gráos.

- Para o efeito de análise estatística, os dados originais foram transformados em arc sen $\sqrt{\frac{x+1}{100}}$ e arc sen $\sqrt{\frac{x}{100}}$, respectivamente para emergência de plântulas e viabilidade de sementes.

Ns Médias comparadas com a testemunha nas colunas, não diferem significativamente pelo teste bilateral de Dunnet, ao nível de $1 \%$ de probabilidade.

** Médias comparadas com a testemunha nas colunas, diferem significati vamente pelo teste bilateral de Dunnet ao nivel de $1 \%$ de probabilidade.

possível encontrar variação de germinação em função de diferentes posições das sementes na mesma.

Os dados encontrados neste trabalho indicam que as aplicações de compostos herbicidas, como imidazolinonas e sulfoniluréias, no florescimento podem proporcionar grande redução na produção de frutos e de sementes, o que poderia impedir, por conseguinte, o reabastecimento do banco de sementes de plantas daninhas no solo, mostrando assim, uma possibilidade de manejo destas no ambiente agrícola.

Em decorrência dos resultados apresentados e discutidos, pode-se concluir que as aplicações dos compostos imazaquin, imazethapyr e chlorimuron durante o florescimento de quinquilho proporcionaram redução na produção de frutos e de sementes por planta e, também decréscimo no peso das sementes.
TABELA 5 - Emergência das plântulas e viabilidade das sementes de quinquilho oriundas de plantas-mãe pulverizadas por herbicidas na fase reprodutiva. Porto Alegre, RS, 1991/92.

\begin{tabular}{|c|c|c|}
\hline Tratamentos & \multicolumn{2}{|c|}{ Características } \\
\hline Fatores e níveis & $\begin{array}{c}\text { Emergência } \\
\text { das plântulas } \\
(\%)\end{array}$ & $\begin{array}{c}\text { Viabilidade } \\
\text { das sementes } \\
(\%)\end{array}$ \\
\hline \multicolumn{3}{|l|}{ Herbicidas } \\
\hline Imazaquin & $17,8 \mathrm{a}^{* *}$ & 53,3 a \\
\hline Imazethapyr & 11,9 a & 41,8 a \\
\hline Chlorimuron & 18,9 a & 50,4 a \\
\hline Metsulfuron & 23,9 a & 56,7 a \\
\hline \multicolumn{3}{|l|}{$\operatorname{Doses}^{* * *}$} \\
\hline Meia-dose & 18,6 a & 52,2 a \\
\hline Dose-plena & 17,4 a & 48,9 a \\
\hline \multicolumn{3}{|l|}{ Épocas de aplicaçẫo } \\
\hline Florescimento & 18,9 a & 44,7 a \\
\hline Enchimento de gräos & $17,0 \mathrm{a}$ & 56,4 a \\
\hline CV $(\%)$ & 27,6 & 22,7 \\
\hline
\end{tabular}

- Para o efeito de análise estatística, os dados originais foram transformados $\mathrm{em}$ arc sen $\sqrt{\frac{x+1}{100}} \mathrm{e}$ arc sen $\sqrt{\frac{x}{100}}$, respectivamente para emergência de plântulas e viabilidade de sementes.

*. Médias comparadas dentro de cada fator nas colunas, seguidas de mesma letra, não diferem significativamente entre si pelo teste de Duncan, ao nível de $1 \%$ de probabilidade.

*** Correspondentes à metade da dose usual e à dose recomendada, respectivamente.

Já as aplicações realizadas no enchimento de grãos mostraram-se muito tardias em afetar a produção de frutos e de sementes. A viabilidade e a emergência das sementes de quinquilho não foram modificadas em função das pulverizações herbicidas. Herbicidas aplicados na fase reprodutiva de plantas daninhas permitem reduzir a perpetuação das mesmas, reduzindo a produção de sementes.

\section{LITERATURA CITADA}

BEYER, E.M.; DUFFY, M.J.; HAY, J.V.; SCHLUETER, D.D. Sulfonylurea In: KEARNEY, P.C.; KAUFMAN, D.D. (eds). Herbicides: chemistry, degradation, and mode of action. New York: M. Dekker, 1988. v.3, p.117-189.

BINIAK, B.M.; ALDRICH, R.J. Reducing Abutilon theophrasti and Setaria faberi seed production with simulated-roller herbicide applications. Weed Science, Champaign, v34, p.256-259, 1986.

CLAUS, J.S. Chlorimuron-ethyl (Classic): a new broadleaf postemergence herbicide in soybean. Weed Technology, Champaign, v.1, p.114-115, 1987. 
CONGLETON, W.F.; VANCANTFORT, A.M.; LIGNOWSKI, E.M. Imazaquin (Scepter): a new soybean herbicide. Weed Technology, Champaign, v.1, p.186-188, 1987.

FAWCET, R.S.; SLIFE, F.W. Effects of 2,4-D and dalapon on weed seed production and dormancy. Weed Science, Champaign, v.26, p.543-547, 1978.

GARCIA-TORRES, L.; FERNANDEZ-QUINTANILLA, C. Fundamentos sobre malas hierbas y herbicidas. Madrid: Multi-Prensa, 1991. 348p.

GRABE, D.F. Manual do teste de tetrazólio em sementes. Brasilia: AGIPLAN, 1976. 85p.

GRESSEL, J. Herbicide tolerance and resistance: alteration of site of activity. In: DUKE, S.O. (ed). Weed physiology; herbicide physiology. Boca Raton: CRC Press, 1985. v.2, p.159-190.

GUTTERMAN, Y. Flowering, seed development, and the influences during seed maturation on seed germination of annual weeds. In:DUKE, S.O. (ed). Weed physiology; reproduction and ecophysiology. Boca Raton: CRC Press, 1985. v.1, p.1-26.

HENRY, W.T.; BAUMAN, T.T. Interference between soybean (Glycine max) and jimsonweed (Datura stramonium) in Indiana. Weed Technology, Champaign, v.5, p.759-764, 1991.

ISAACS, M.A.; MURDOCK, E.C.; TOLLER, J.E.; WALLACE, S.U. Effects of late-season herbicide applications on sicklepod (Cassia obtusifolia) seed production and viability. Weed Science, Champaign, v.37, p.761-765, 1989.

LEVITT, J.; LOVETT, J.V. Activity of allelochemichals of Datura stramonium L. (thorn-apple) in contrasting soil types. Plant and Soil, v.79, p.181-189, 1984.
LORENZI, H. Plantas daninhas do Brasil; terrestres, aquáticas, parasitas, tóxicas e medicinais. 2. ed. Nov a Odessa: Plantaram, 1991. 440p.

MAUN, M.A.; CAVERS, P.B. Effects of 2,4-D on seed production and embryo development of curly dock. Weed Science, Champaign, v.32, p.533-536, 1969.

PAWLAK, J.A.; MURRAY, D.S.; SMITH, B.S. Influence of capsule age on germination of nondormant Datura stramonium seed. Weed Technology, Champaign, v.4, p.31-34, 1990.

RATNAYAKE, S.; SHAW, D.R. Effects of harvest-aid herbicides on soybean (Glycine max) seed yield and quality. Weed Technology, Champaign, v.6, p.339-344, 1992.

RAY, T.B. Site of action of chlorsulfuron. Plant Physiology, Lancaster, v.75, p.827-831, 1984.

SANCHEZ, R.A.; EYHERABIDE, G.; MIGUEL, L. The influence of irradiance and water deficit during fruit development on seed dormancy in Datura ferax L. Weed Research, Ontario, v.21, p.127-132, 1981.

SHANER, D.L.; ANDERSON, P.C.; STIDHAM, M.A. Imidazolinones: Potent inhibitors of acetohydroxyacid synthase. Plant Physiology, Lancaster, v.76, p.545546, 1984.

TAYLORSON, R.B. Control of seed production in three annual grasses by dimethylarsinic acid. Weeds, Champaign, v.14, p.207-210, 1966.

WEAVER, S.O.; WARWICK, S.I. The biology of canadian weeds. 64. Datura stramonium L. Canadian Journal of Plant Science, Ontario, v.64, p.979-991, 1984. 